\title{
Cardiac Postoperative Use of High-Flow Nasal Cannula: A Retrospective Single-Center Study
}

\author{
Emmanuel De Tandt, Marc Nauwynck \\ Department of Intensive Care Medicine, AZ Sint-Jan Hospital, Bruges, Belgium \\ Email: emmanuel.detandt@azsintjan.be
}

How to cite this paper: De Tandt, E. and Nauwynck, M. (2022) Cardiac Postoperative Use of High-Flow Nasal Cannula: A Retrospective Single-Center Study. Open Journal of Thoracic Surgery, 12, 11-20. https://doi.org/10.4236/ojts.2022.121002

Received: January 2, 2022

Accepted: February 12, 2022

Published: February 15, 2022

Copyright $\odot 2022$ by author(s) and Scientific Research Publishing Inc. This work is licensed under the Creative Commons Attribution International License (CC BY 4.0).

http://creativecommons.org/licenses/by/4.0/ (c) (i) Open Access

\begin{abstract}
We aimed to investigate the risk factors and reason for initiation of high-flow nasal cannula (HFNC), its benefit on re-intubation rate, mortality, and length of stay (LOS) in the postoperative cardiac surgery patient in the ICU. Methods: In a retrospective and descriptive study, 200 patients, who underwent cardiac surgery, were randomly included, and screened for initiation of postoperative respiratory support. Demographic patient data and pre-operative patient measurements were sampled. Data concerning the P/F ratio at arrivaland post-extubation, LOS at ICU and overall mortality were sampled. A comparison of those variables was performed between patients with and without need of respiratory support. Results: HFNC was initiated in approximately $22.45 \%$ in 2018 , and $25 \%$ in 2020 , of the patients. Comparing both years didn't reveal a significant rise, but we saw a quicker use of HFNC in 2020. The all-case re-intubation rate and mortality was approximately $3 \%$. The body mass index (BMI) was the only correlation with a higher chance of initiation of HFNC. Other data like age, pre-operative renal- or left ventricle function didn't show a correlation. Conclusion: In case of respiratory insufficiency in the postoperative cardiac surgery setting, HFNC is a worthy first line treatment option which is initiated if conventional oxygen therapy doesn't suffice. The mortality was low, and the mean LOS was 4.38 days. If respiratory support was started with HFNC mean LOS rose to 8.35 days. The BMI seems to have a correlation with the development of respiratory failure, which confirms the latest recommendation to start preventive HFNC in the post-extubation cardiac surgery setting and which could be implemented in the daily practice.
\end{abstract}

\section{Keywords}

Postoperative Respiratory Failure, Cardiac Surgery, HFNC, Noninvasive Ventilation, Reintubation 


\section{Introduction}

In the management of acute respiratory failure, heated, humidified, high-flow nasal cannula (HHHFNC or HFNC) has gained increasing popularity. It has filled a gap between facemask oxygen and non-invasive mechanical ventilation (NIV), even without evidence of benefit [1].

HFNC has the ability to deliver an inspired oxygen fraction between 0.21 and 1.0 , with a gas flow of $60 \mathrm{~L} / \mathrm{min}$. It delivers a low level of positive pressure in the upper airways and hereby increases the airway pressure and the end-expiratory lung volume, diminishes the respiratory dead space, the work of breathing and respiratory rate [1] [2] [3] [4]. Because of these physiological benefits, it can improve oxygenation and comfort after extubation, and prevent post-extubation failure and reintubation [2] [3] [4] [5].

In 2017 the ERS/ATS guidelines supported the use of NIV in the postoperative setting. In supra-diaphragmatic surgery, NIV decreases the need for re-intubation and in-hospital mortality. Studies showed that the use of HFNC, compared with NIV, did not result in a higher need for re-intubation [3], hereby being recommended in high-risk patients in the prevention of post-extubation respiratory failure, as after cardiothoracic surgery [2] [6] [7] [8]. If post-extubation respiratory failure occurs, the ERS/ATS 2017 guidelines do not suggest use of noninvasive ventilation [3].

We aimed to investigate the use of HFNC at a high-level cardiothoracic tertiary center, and explore the reasons of respiratory failure, its benefit on re-intubation rate, mortality, and length of stay (LOS). We therefore performed a retrospective and descriptive study to explore the correlation between multiple demographic and pathophysiological measurements in the intensive care unit (ICU) in post-cardiac surgery patients. We also studied whether a different result could be found when comparing a population treated in 2018 versus a more recent population (2020) to explore shifts in correlations over time.

\section{Methods}

In a retrospective and descriptive study, 200 patients, who underwent cardiac surgery at a high-level cardiothoracic center, in 2018 and 2020, were randomly included.

2018 was chosen as the comparative year because it was the first year where all data could be sampled from an electronic database.

Demographic data as age, sex, BMI, pre-operative left ventricle function, -pulmonary function and -renal function were sampled. Concerning this study, we further sampled other variables as the P/F ratio at arrival- and post-extubation at the ICU, the APACHE II score at ICU-admission and -discharge, duration of weaning, the number of patients in need of respiratory support in the postoperative phase (HFNC, bilevel NIV or reintubation), LOS at ICU and-in hospital, the need of diuretic-or antibiotic treatment and the mortality. A comparison of those variables was executed between patients with and without need of respira- 
tory support, and HFNC in particular. All these in-hospital data were obtained from an electronic database, linked to the program used in the ICU. Descriptive statistical analysis of these data was performed by excel.

The local ethics committee (Commissie voor Ethiek; AZ Sint-Jan Brugge) reviewed the study and gave approval (Approval 2937) to this retrospective noninterventional study to be performed in this center.

\section{Results}

\subsection{Demographic Patient Findings}

In 2018 and 2020, 200 patients who underwent a CABG, heart valve surgery, or combination were sampled and included. No exclusion was made at this point. Demographic data and patients related measurements are presented in Table 1.

In 2020 there were less CABG-procedures. In 2020 there was a rise in single valvular procedures. Single valve surgery mainly consisted of surgical aortic valve replacement.

ICU mean LOS was 5.25 days in 2018 versus 6.27 in 2020.

The mean total LOS in hospital was 11.28 days in 2018 and 11.71 days in 2020. Overall mortality was $2 \%$ in 2018 and $3 \%$ in 2020.

The mean APACHE II score on admission was 11.36 in 2018, and 14.27 in 2020. The mean APACHE II score at ICU-discharge was 7.49 in 2018 compared to 10.55 in 2020.

\subsection{Postoperative Findings: (Diagram 1)}

Weaning: $99 \%$ of the patients were weaned from the ventilator in 2018; while $97 \%$ were weaned in 2020. In 2020, one patient had emergent mitral valve surgery after an unsuccessful percutaneous mitral valve repair (mitraclip) and died of heart failure shortly after. A second patient couldn't be weaned because of severe emphysema and died. A third patient died due to an acute distributive shock. In 2018, one patient suffered a complicated postoperative course, needing 2 reinterventions due to tamponade. In both years, one patient needed weaning by tracheostomy because of a protracted weaning phase.

All other patients were successfully weaned. In 2018, 83.7\% had a fluent weaning process, compared to $87.5 \%$ in 2020 . The mean duration of weaning in those patients was around 320 minutes. In 2018, the mean P/F ratio on admission was 292 and 329 after extubation in patients with a fluent weaning. In case of a prolonged weaning phase, mean P/F ratio was 181, at admission, and 231 after extubation.

Unlike 2018, in 2020, the mean P/F ratio at ICU admission in an uncomplicated weaning process was 289 and 339 after extubation. Patients who had a prolonged weaning process had quite similar mean $\mathrm{P} / \mathrm{F}$ ratios.

No respiratory support during the postoperative setting: In 2018 and 2020, when patients didn't need postoperative respiratory support (75\% of the cases), the mean LOS was respectively 4.09 and 4.67 days. 
The mean time till extubation amounted 358 minutes in 2018 and 407 minutes in 2020. The mean P/F ratio at ICU admission of this group was 305 in 2018 and 304 in 2020, while post weaning the mean P/F ratio was 353 in 2018 and 357 in 2020.

Table 1. Demographic and post-operative patients related measurements, with comparison of year 2018 and 2020 (SD: standard deviation).

\begin{tabular}{|c|c|c|c|c|c|}
\hline \multirow{2}{*}{ Variables of interest } & & \multicolumn{2}{|c|}{2018} & \multicolumn{2}{|c|}{2020} \\
\hline & & Mean & SD & Mean & SD \\
\hline \multirow[t]{2}{*}{ Sex } & Male & $73 \%$ & l & $73 \%$ & l \\
\hline & Female & $27 \%$ & I & $27 \%$ & l \\
\hline Mortality & Overall & $2 \%$ & l & $3 \%$ & l \\
\hline \multirow[t]{4}{*}{ Age } & Overall & 67.06 & 10.79 & 69.99 & 11.22 \\
\hline & $<59$ & $24 \%$ & l & $18 \%$ & l \\
\hline & $60-79$ & $67 \%$ & / & $63 \%$ & l \\
\hline & $>80$ & $9 \%$ & I & $19 \%$ & l \\
\hline \multirow[t]{3}{*}{ Operation type } & CABG & $63 \%$ & I & $45 \%$ & l \\
\hline & Heart valve surgery & $25 \%$ & l & $32 \%$ & l \\
\hline & Combination & $12 \%$ & I & $23 \%$ & l \\
\hline \multirow[t]{3}{*}{ BMI } & Overall & 27.82 & 4.42 & 28.12 & 4.04 \\
\hline & No resp support & 27.53 & 4.44 & 27.87 & 4.22 \\
\hline & HFNC & 28.85 & 4.34 & 28.52 & 3.59 \\
\hline \multirow[t]{3}{*}{ Renal function } & Overall & 1.02 & 0.47 & 1.06 & 0.31 \\
\hline & No resp support & 0.998 & 0.31 & 1.06 & 0.32 \\
\hline & HFNC & 1.12 & 0.81 & 1.06 & 0.28 \\
\hline \multirow[t]{3}{*}{$\mathrm{P} / \mathrm{F}$ ratio at admission } & Overall & 274.7 & 112.8 & 287.4 & 98.04 \\
\hline & No resp support & 304.88 & 106.9 & 303.9 & 93.98 \\
\hline & HFNC & 176.64 & 74.58 & 242.5 & 96.73 \\
\hline \multirow{3}{*}{$\begin{array}{l}\mathrm{P} / \mathrm{F} \text { ratio post } \\
\text { extubation }\end{array}$} & Overall & 313.7 & 113.3 & 335 & 109.3 \\
\hline & No resp support & 353.42 & 97.18 & 357.2 & 101.9 \\
\hline & HFNC & 181.81 & 44.71 & 268.2 & 105.4 \\
\hline \multirow[t]{2}{*}{ APACHE II score } & Admission & 11.36 & 4.77 & 14.27 & 4.19 \\
\hline & Discharge & 7.49 & 3.94 & 10.55 & 3.64 \\
\hline \multirow[t]{3}{*}{ LOS ICU } & Overall & 5.25 & 4.34 & 6.27 & 6.42 \\
\hline & No resp support & 4.09 & 1.77 & 4.67 & 1.71 \\
\hline & HFNC & 7.77 & 4.43 & 8.92 & 5.59 \\
\hline LOS Hospital & Overall & 11.28 & 6.14 & 11.71 & 7.97 \\
\hline
\end{tabular}




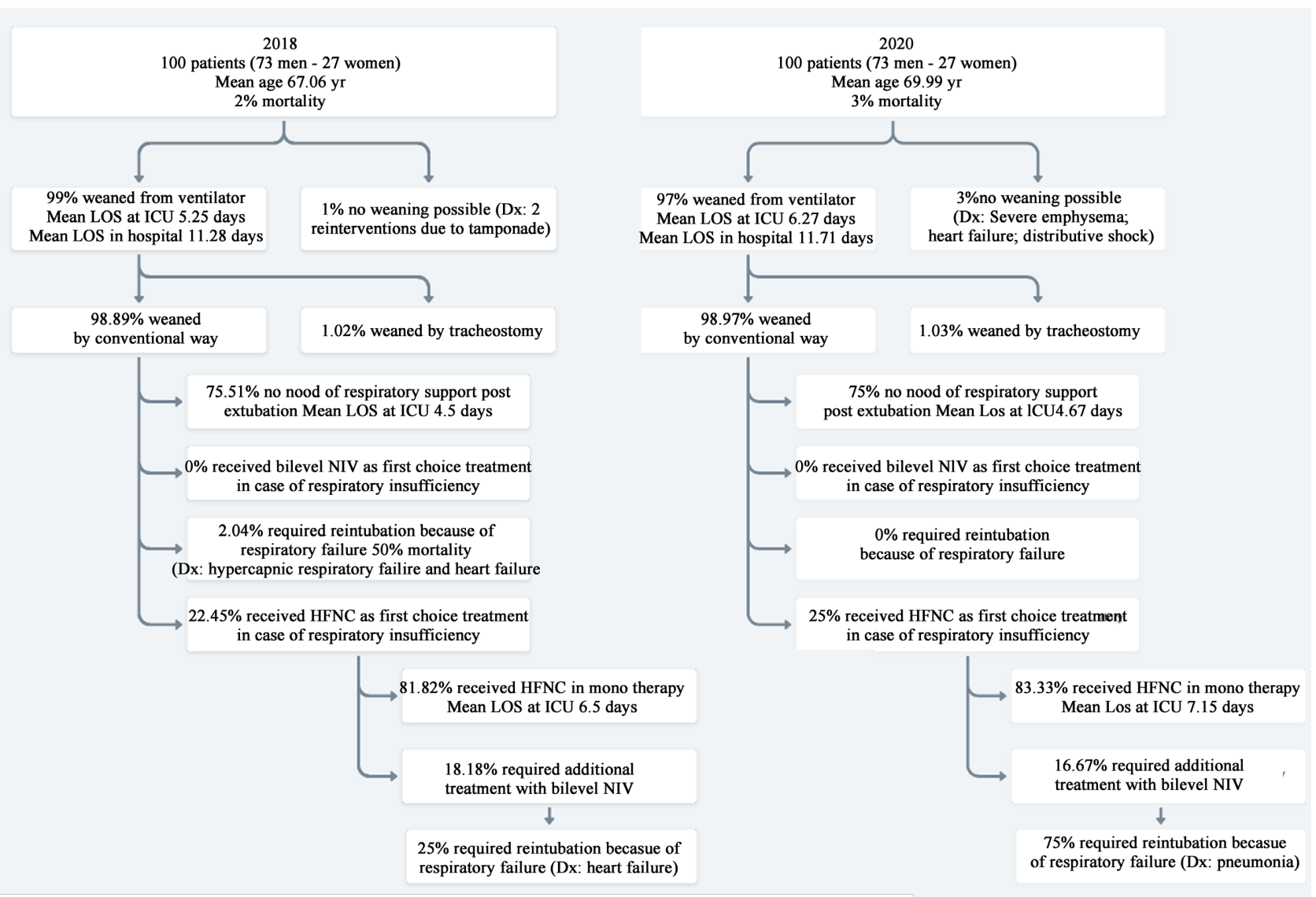

Diagram 1. Consort diagram of 2018 and 2020.

HFNC as postoperative respiratory support treatment: In $2018,22.45 \%$ of the conventionally weaned patients needed initiation of HFNC as respiratory support, while in 2020 this counted for $25 \%$.

The mean $\mathrm{P} / \mathrm{F}$ ratio, if a patient needed HFNC as respiratory support, was 176.64 at ICU admission in 2018, and 242.5 in 2020. The mean time needed for extubation was 678.1 minutes in 2018, while 401.8 minutes in 2020. When extubated, the mean P/F ratio in those patients was 181.81 in 2018 and 268.2 in 2020.

When starting HFNC as respiratory support, the mean length of stay at ICU was prolonged to approximately 7.77 days in 2018 and 8.92 days in 2020 .

In this study, if patients were treated with HFNC because of hypoxemia, mortality was $0 \%$ in 2018 and 2020.

Bilevel NIV as postoperative respiratory support treatment: In this single-center study, no patients received BiPAP, as a first choice treatment, in the prevention of postoperative respiratory failure. In 2018, 4.04\% of the weaned patients received NIV but only in case of respiratory deterioration on HFNC (18.18\%). $25 \%$ of them needed reintubation because of insufficient improvement with NIV. In 2020 we counted $4.12 \%$ of the weaned patients receiving bilevel NIV, following HFNC (16.67\%). Of these patients $75 \%$ needed reintubation because of respiratory failure.

Re-intubation rate: in 2018, and $2020,3 \%$ of the weaned patients needed 
reintubation. In 2018 66\% of them didn't receive NIV nor HFNC-treatment before reintubation. The causes were acute heart failure because of right ventricular dysfunction and hypercapnic respiratory failure, 1 patient died because of heart failure.

In 2020, all patients with respiratory failure first received treatment with HFNC and NIV before getting re-intubated. Reasons for reintubation in these patients was a diagnose of pneumonia with severe hypoxic respiratory failure.

Reintubation occurred approximately at day 2 post-extubation, in both 2018 and 2020.

Initiation of diuretic treatment: In $2018,49 \%$ of the patients had a suspicion of fluid overload, and signs of congestion on chest X-ray. In 2020 a comparable result of 51\% was observed. Over $90 \%$ received diuretic treatment with diuretics.

If respiratory support was initiated, $72.73 \%$ received diuretic treatment in 2018 , and $70.83 \%$ in 2020 . Of the patients who didn't receive respiratory support, $39.19 \%$ received diuretic treatment in 2018 , and $44.4 \%$ in 2020 .

Initiation of antibiotic treatment: In $2018,31 \%$ of the patients had a suspicion of pneumonia on chest X-ray, compared to 27\% in 2020. Despite the lower suspicion in 2020, 40\% of all patients received antibiotics, while in 2018 this counted for $30 \%$ of the patients. Other reasons for antibiotic treatment included an elevated CRP (C-Reactive Protein) and raised temperature.

If respiratory support was initiated, $59.09 \%$ received antibiotic treatment in 2018, and $66.7 \%$ in 2020. Patients without need for respiratory support received antibiotic treatment in $18.91 \%$ of the cases in 2018, and $30.56 \%$ in 2020 .

Correlations: To distinguish if some patient risk factors could predict a higher need of initiation of HFNC in the postoperative setting, a propensity score matching was performed.

The sex of the patient was not correlated with the initiation HFNC.

Aging was not a predictor for a higher need of ventilatory support.

The weight was predictive for the need of ventilatory support. The mean BMI of the patients without need of respiratory support was 27.53 and 27.87 in respectively 2018 and 2020. While, if HFNC was required, the mean BMI rose to 28.85 and 28.52 in 2018 and 2020.

Pre-operative lung function could also give us a clue to expect postoperative respiratory problems, but due to incomplete data no conclusion could be made.

If the pre-operative left ventricle function was lower than normal range; $20 \%$ received respiratory support in 2018; while it counted for $31.8 \%$ in 2020.

Decreased renal function was not associated with the need for HFNC.

Investigation of the $\mathrm{P} / \mathrm{F}$ ratio after extubation may be indicative for the need of respiratory support. When looking at the results of 2018; a P/F ratio lower than 250 had a higher incidence of initiating HFNC. In 2020 a less clear-cut P/F ratio was visible. Although if the $\mathrm{P} / \mathrm{F}$ ratio was lower than 300 a higher incidence of starting HFNC could also be seen. In the patients with a P/F ratio between 350 and 400 post-extubation; $15.4 \%$ of them needed respiratory support. But as a 
footnote, in those patients HFNC was started only after 2 days because of the development of a pneumonia.

\section{Discussion}

Acute respiratory failure, after cardiothoracic surgery is common, and associated with increased morbidity and mortality. CPAP and bilevel NIV are known to be effective at improving lung aeration and arterial oxygenation and decreasing the amount of atelectasis without adverse effects. Both treatments have shown to be beneficial in comparison to conventional oxygen therapy regarding the re-intubation rate, ICU-acquired infections, and mortality [9]. Because of its physiological benefits, HFNC has become a treatment for acute hypoxemic respiratory failure (first-line ventilatory support, pre-oxygenation, post-extubation and palliative care) [1].

Despite the small study population, this retrospective study demonstrated the frequent- and ease of use of HFNC in the post-operative care setting. If a patient was in need of respiratory support in the postoperative setting, the primary choice was HFNC, which counted for approximately one out of four of all postoperative patients. A minority of the patients received bilevel NIV as respiratory support, only after failure of HFNC treatment.

HFNC is easy to apply and has a better patient compliance, compared to the use of noninvasive ventilation [1]. But mind the combination of NIV-treatment with a high respiratory drive which may lead to high tidal volumes with excessive transpulmonary pressures contributing to patient self-inflicted lung injury (P-SILI) and a higher mortality [10] [11].

A study of Stephan et al. in 2015 demonstrated that the use of high-flow nasal cannula therapy, compared with intermittent bilevel NIV, did not result in increased treatment failure defined as need for re-intubation [3] [6].

The global reintubation rate and mortality in this study was low. If the low reintubation rate is a result of the high use of HFNC is a possibility, but difficult to conclude from our study. Nevertheless, we observe that there is a low reintubation rate when started with HFNC, which may suggest a positive influence.

Guidelines further suggest a combination of bilevel NIV and HFNC for the prevention of post-extubation respiratory failure in high-risk patients [12]. Adjunctive NIV has proven to be beneficial in facilitating the weaning from mechanical ventilation in patient with hypercapnic respiratory failure, but in this setting HFNC is not indicated [3].

Nevertheless, no matter which treatment is initiated, it remains of paramount importance that both treatment options require a careful selection of patients, and rigorous monitoring during use, in order to avoid delayed intubation, which, if indicated, is associated with an increased mortality [3] [13].

If no respiratory support was needed, mean LOS in the ICU was almost indifferent between both years (respectively 4.09 to 4.67 days). But if respiratory support was initiated with HFNC, it increased significantly to a mean LOS of 
7.78 days in 2018 and 8.92 days in 2020 .

Further interpretation of the study results could also help us conclude that there seems to be a shift in a quicker initiation of HFNC in 2020, compared to 2018, with a likewise faster extubation ratio, even with lower $\mathrm{P} / \mathrm{F}$ ratio.

When investigating the $\mathrm{P} / \mathrm{F}$ ratio on arrival in the ICU and post-extubation, we could conclude that the first $\mathrm{P} / \mathrm{F}$ ratio at admission is of low importance. Even with low values at admission, spontaneous recruitment was seen during the first hours, without clear relation with the initiation of respiratory support.

A logical assumption that the first $\mathrm{P} / \mathrm{F}$ ratio post-extubation being an important marker for the need of HFNC, has been shown in this study. We could conclude that a $\mathrm{P} / \mathrm{F}$ ratio lower than 250 post-extubation was predictive for the need of HFNC. Could a longer intubation time be beneficial to overcome this need? We presume this answer to be negative, since patients in 2020 were extubated sooner than in 2018, with even lower P/F ratio, and no significant increased need for ventilatory support. Starting HFNC if the first P/F ratio being lower than 250 and comparing its mortality, reintubation rate and LOS, could be useful in further studies. Because of these results, we could conclude that time to extubation can be shortened by the use of HFNC.

Diuretic therapy was started in $50 \%$ of all the patients, mostly because of signs of congestion or low diuresis during ICU admission.

A quite remarkable finding was the high and rising use of antibiotic treatment, with a significant difference between 2018 and 2020, where more antibiotics were prescribed even without hard evidence of pulmonary infection. We also noted that if respiratory support was started, a higher proportion of these patients received diuretics and/or antibiotics.

Finding risk factors which could predict the need of initiation of HFNC in the postoperative setting would be of great help for practice. Unfortunately, this study couldn't find major correlations. Nor age, sex, pre-operative ASA-score, or pre-operative renal function or left ventricle function predict the need of HFNC use.

A possible correlation is patients' weight, a higher BMI being associated with HFNC use. This corresponds to the research of Chaudhuri et al. in 2020 [14], and to the latest recommendations of the 2020 ERS/ATS guidelines. One could advise to start HFNC post-extubation in patients with a high BMI [8]. It has even been recommended to start HFNC or NIV in high risk and/or obese patients undergoing cardiac- or thoracic surgery to prevent postoperative respiratory failure [8].

Pre-operative decreased pulmonary function could also play a role in the need of HFNC, but because of incomplete data no conclusion could be.

CABG remains the standard of care for multivessel coronary disease, and in particular three-vessel or left main coronary artery disease [15] [16].

Our study revealed a decrease in CABG-procedures between 2018 and 2020, which presumably is explained by the increasing percutaneous coronary interventions, and the higher incidence of valve replacements. 
The mean age in this study is rising, confirming the worldwide trend [15]. Despite the increasing use of TAVR (transcatheter aortic valve replacement), this study still found an increase in surgical valve replacement.

\section{Conclusions}

Cardiac surgery is a safe procedure, with low morbidity and mortality, and with a ICU mean LOS of approximately 4.38 days.

In the postoperative setting, in case of respiratory insufficiency, HFNC is proven to be a worthy first line treatment which is initiated if conventional oxygen therapy doesn't seem to be sufficient, before initiating NIV. If respiratory support with HFNC was initiated, mean LOS rose to 8.35 days, with an increased use in antibiotic- and diuretic therapy.

We cannot conclude from our study that HFNC use prevents reintubation, but there is a positive effect. Time to extubation can also be shortened.

A correlation is found between the BMI of a patient and the development of respiratory failure, which confirms the latest recommendation to start preventive HFNC in the post-extubation cardiac surgery setting for patients with an elevated BMI or other high-risk factors. An ideal P/F ratio for initiation of HFNC hasn't been found, although there is a higher incidence if lower than 250. Further studies could be useful to compare the diagnose of a pneumonia, initiation of antibiotics, mortality, reintubation rate and LOS as per $\mathrm{P} / \mathrm{F}$ ratio with or without treatment with HFNC.

\section{Limitations}

This was a retrospective study with a small number of patients.

\section{Conflicts of Interest}

The authors declare no conflicts of interest regarding the publication of this paper.

\section{References}

[1] Ricard, J.D., Roca, O., Lemiale, V., Corley, A., Braunlich, J., Jones, P., et al. (2020) Use of Nasal High Flow Oxygen during Acute Respiratory Failure. Intensive Care Medicine, 46, 2238-2247. https://doi.org/10.1007/s00134-020-06228-7

[2] Theologou, S., Ischaki, E., Zakynthinos, S.G., Charitos, C., Michopanou, N., Patsatzis, S., et al. (2021) High Flow Oxygen Therapy at Two Initial Flow Settings versus Conventional Oxygen Therapy in Cardiac Surgery Patients with Postextubation Hypoxemia: A Single-Center, Unblinded, Randomized, Controlled Trial. Journal of Clinical Medicine, 10, 2079. https://doi.org/10.3390/jcm10102079

[3] Rochwerg, B., Brochard, L., Elliott, M.W., Hess, D., Hill, N.S., Nava, S., et al. (2017) Official ERS/ATS Clinical Practice Guidelines: Noninvasive Ventilation for Acute Respiratory Failure. European Respiratory Journal, 50, Article ID: 1602426. https://doi.org/10.1183/13993003.02426-2016

[4] Levy, S., Alladina, J., Hibbert, K., Harris, R., Bajwa, E. and Hess, D. (2016) High-Flow oxygen Therapy and Other Inhaled Therapies in Intensive Care Units. 
The Lancet, 387, 1867-1878. https://doi.org/10.1016/S0140-6736(16)30245-8

[5] Hernández, G., Vaquero, C., González, P., Subira, C., Frutos-Vivar, F., Rialp, G., et al. (2016) Effect of Postextubation High-Flow Nasal Cannula vs Conventional Oxygen Therapy on Reintubation in Low-Risk Patients: A Randomized Clinical Trial. JAMA, 315, 1354-1361. https://doi.org/10.1001/jama.2016.2711

[6] Stéphan, F., Barrucand, B., Petit, P., Rézaiguia-Delclaux, S., Médard, A., Delannoy, B., et al. (2015) High-Flow Nasal Oxygen vs Noninvasive Positive Airway Pressure in Hypoxemic Patients after Cardiothoracic Surgery: A Randomized Clinical Trial. JAMA, 313, 2331-2339. https://doi.org/10.1001/jama.2015.5213

[7] Hernández, G., Vaquero, C., Colinas, L., Cuena, R., González, P., Canabal, A., et al. (2016) Effect of Postextubation High-Flownasal Cannula vs Noninvasive Ventilation on Reintubation and Postextubation Respiratory Failure in High-Risk Patients. A randomized Clinical Trial. JAMA, 316, 1565-1574.

https://doi.org/10.1001/jama.2016.14194

[8] Rochwerg, B., Einav, S., Chaudhuri, D., Mancebo, J., Mauri, T., Helviz, Y., et al. (2020) The Role for High Flow Nasal Cannula as a Respiratory Support Strategy in Adults: A Clinical Practice Guideline. Intensive Care Medicine, 46, 2226-2237. https://doi.org/10.1007/s00134-020-06312-y

[9] Zayed, Y., Kheiri, B., Barbarawi, M., Rashdan, L., Gakhal, I., Ismail, E., et al. (2020) Effect of Oxygenation Modalities among Patients with Postoperative Respiratory Failure: A Pairwise and Network Meta-Analysis of Randomized Controlled Trials. Journal of Intensive Care, 8, 51. https://doi.org/10.1186/s40560-020-00468-X

[10] Grieco, D.L., Maggiore, S.M., Roca, O., Spinelli, E., Patel, B.P., Thille, A.W., et al. (2021) Non-Invasive Ventilatory Support and High-Flow Nasal Oxygen as First-Line Treatment of Acute Hypoxemic Respiratory Failure and ARDS. Intensive Care Medicine, 47, 851-866. https://doi.org/10.1007/s00134-021-06459-2

[11] Frat. J.P., Ragot, S., Coudroy, R., Robert, R. and Thille, A.W. (2016) A. Tidal Volume and Non-Invasive Ventilation Failure-Authors' Reply. The Lancet Respiratory Medicine, 4, e52. https://doi.org/10.1016/S2213-2600(16)30328-9

[12] Thille, A.W., Muller, G., Gacouin, A., Coudroy, R., Descavéke, M., Sonneville, R., et al. (2019) Effect of Postextubation High-Flow Nasal Oxygen with Noninvasive Ventilation vs High-Flow Nasal Oxygen Alone on Reintubation among Patients at High Risk of Extubation Failure: A Randomized Clinical Trial. JAMA, 322, 1465-1475. https://doi.org/10.1001/jama.2019.14901

[13] Bellani, G., Laffey, J., Pham, T., Madotto, F., Fan, E., Brochard, L., et al. (2017) Noninvasive Ventilation of Patients with Acute Respiratory Distress Syndrome. Insights from the LUNG SAFE Study. American Journal of Respiratory and Critical Care Medicine, 195, 67-77. https://doi.org/10.1164/rccm.201606-1306OC

[14] Chaudhuri, D., Granton, D., Wang, D., Burns, K., Helviz, Y., Einav, S., et al. (2020) High-Flow Nasal Cannula in the Immediate Postoperative Period: A Systematic Review and Meta-Analysis. Chest, 158, 1934-1946. https://doi.org/10.1016/j.chest.2020.06.038

[15] Melly, L., Torregrossa, G., Lee, T., Jansens, J. and Puskas J. (2018) Fifty Years of Coronary Artery Bypass Grafting. Journal of Thoracic Disease, 10, 1960-1967. https://doi.org/10.21037/jtd.2018.02.43

[16] Habib, R., Dimitrova, K., Badour, S., Yammine, M., El-Hage-Sleiman, A., Hoffman, D., et al. (2015) CABG versus PCI: Greater Benefit in Long-Term Outcomes with Multiple Arterial Bypass Grafting. Journal of the American College of Cardiology, 66, 1417-1427. https://doi.org/10.1016/j.jacc.2015.07.060 